\title{
Synergistic Effect of Influenza A Virus on Endotoxin-Induced Mortality in Rat Pups: A Potential Model for Sudden Infant Death Syndrome
}

\author{
JANE BLOOD-SIEGFRIED, ABRAHAM NYSKA, HOLLY LIEDER, MIJEOM JOE, LIBIA VEGA, \\ RACHEL PATTERSON, AND DORI GERMOLEC \\ Environmental Immunology Laboratory, National Institute of Environmental Health Sciences, Research \\ Triangle Park, North Carolina 27709, U.S.A. [J.B.-S., A.N., H.L., L.V., R.P., D.G.]; Duke University \\ School of Nursing, Durham. North Carolina 27707, U.S.A. [J.B.-S., H.L., M.J.]; and CINVESTAV, \\ Farmacobiología, Sección Externa de Toxicología, Zacateneo, Mexico D. F. 07360 [L.V.]
}

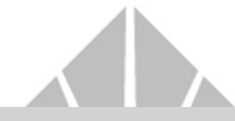

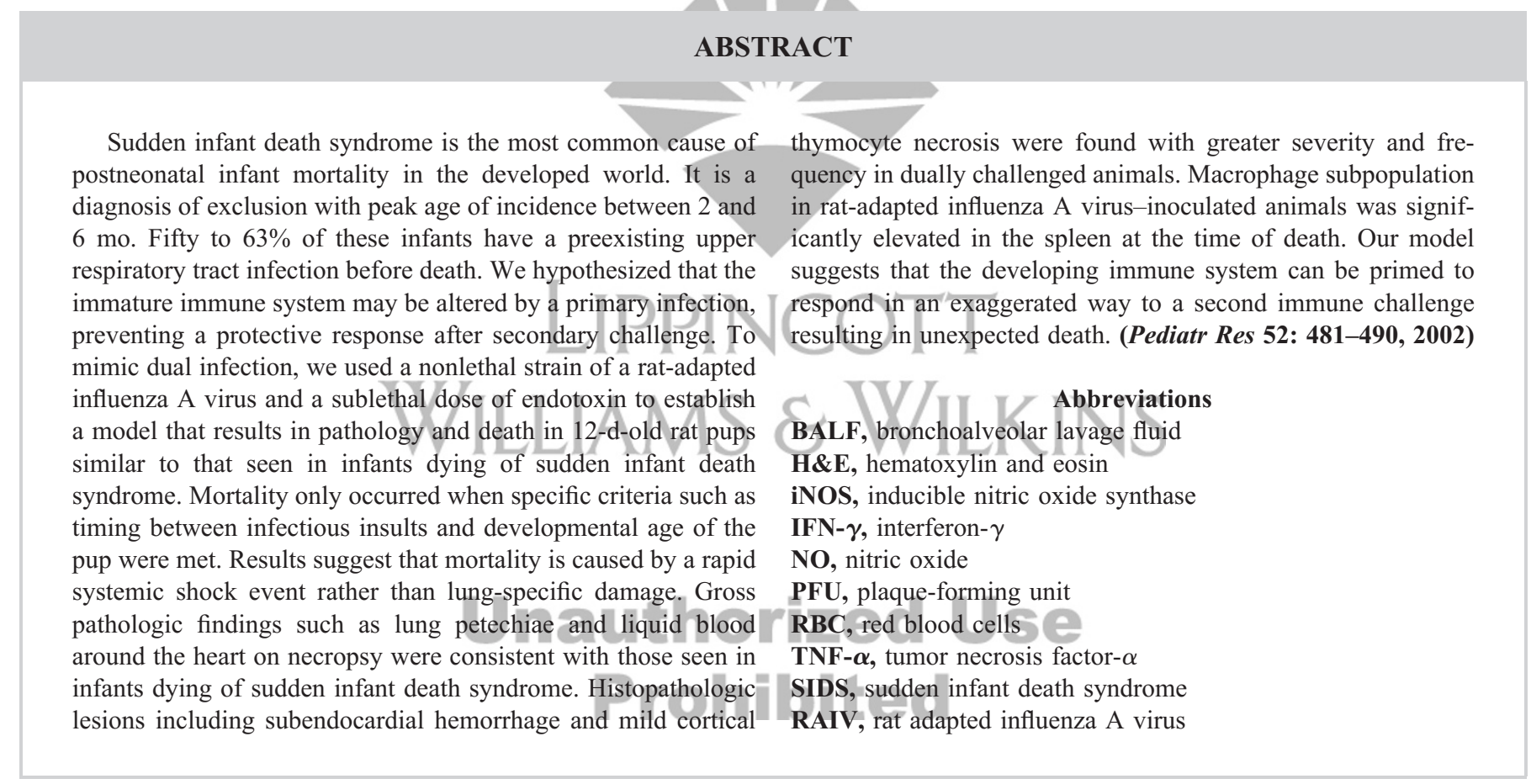

SIDS is the most common cause of mortality in infants between $1 \mathrm{wk}$ and $1 \mathrm{y}$ of age in the developed world (1). It is a diagnosis of exclusion often defined as the sudden death of an infant not explained by symptoms of illness or autopsy findings. Factors thought to increase susceptibility include exposure to tobacco smoke and prone sleeping, with peak age of incidence between 2 and 6 mo (1). Although one of the defining characteristics is an absence of symptoms, 50 to $63 \%$ of SIDS infants had a mild viral infection before death $(2,3)$.

Received June 1, 2001; accepted February 12, 2002.

Correspondence: Jane Blood-Siegfried, D.N.Sc., C.P.N.P., Duke University, School of Nursing, Box 3322, Durham, NC 27710, U.S.A.; e-mail blood002@mc.duke.edu

Supported in full by the National Institute of Environmental Health Sciences.

DOI: 10.1023/01.PDR.0000028250.96650.D7
In many cases, parents have consulted a health-care provider in the weeks preceding death, reporting symptoms of upper respiratory and gastrointestinal illness $(2,3)$. Blackwell and Weir (1) have suggested that SIDS is a "patho-physiologic response elicited by combinations of microbial products and/or cigarette smoke during a developmental stage when infants' endocrine responses are less able to 'damp down' the effects of inflammatory mediators."

Gram-negative bacteria, particularly Escherichia coli and superantigen-producing strains of Gram-positive bacteria, were found on autopsy in a large number of SIDS infants $(3,4)$. There is a significant relationship between endotoxin levels in the blood and signs of inflammation in infants dying of SIDS (5). In addition, SIDS is more prevalent in populations in 
which infections are common, in association with influenza A outbreaks, and during winter months, when viral infections are prominent $(6,7)$.

Toxins from these organisms induce cardiovascular abnormalities and activate the release of the proinflammatory cytokines TNF- $\alpha$ and IFN- $\gamma$ by immune cells (8). Some human infants may overreact immunologically because of predisposing factors or underlying host vulnerability, succumbing to an otherwise nonpathologic event (9). Trying to pinpoint a particular toxin or group of toxins has thus far been nonproductive, and various combinations of bacterial or viral insults may play a role in the induction of sudden unexplained deaths. It is suspected that many viruses can exacerbate clinical signs and symptoms seen with bacterial infections such as seen with influenza virus and Streptococcus pneumoniae or Staphylococcus aureus (10-12).

Prone sleeping, an important risk factor for SIDS, may cause impairment of gas exchange; however, there are also data to suggest a prone position may exacerbate the response to infection. During times of viral infection, prone position can increase airway temperature, stimulating bacterial infection and bacterial toxin production (13). The nasal septal temperatures of children who had no evidence of respiratory tract infection were measured in both the prone and erect positions and found to be significantly higher in the prone position (14). Combined with viral infection, prone sleeping would have an even greater effect. Infants with an upper respiratory infection placed in the prone position for sleeping have increased bacterial colonization on early morning swabs. Gram-negative bacilli, particularly Haemophilus influenza and Neisseria species, were more common than in supine sleepers. Highest counts were measured in prone sleepers with a concurrent upper respiratory infection (4).

Given the paucity of immune data related to SIDS, we have developed an animal model to mimic dual infection, using a nonlethal strain of influenza A virus and a sublethal dose of endotoxin. Particular attention has been paid to the hypothesis that influenza A virus changes the normal immune response to endotoxin by regulating the production of TNF- $\alpha$ and other inflammatory cytokines that normally promote a TH-1 type response. The immature immune system is either unable to tolerate these changes or unable to dampen the response, resulting in death. We have defined similarities of SIDS pathology in human infants and that seen in this model and begun to examine basic immune factors associated with this death.

\section{METHODS}

Virus. RAIV, developed from influenza A/Port Chalmers/ 1/73 (H3N2) virus, initially purchased from American Type Culture Collection and adapted by successive passages in allantoic fluid of chicken eggs, was a gift from Dr. Gary Burleson (Burleson Research Technologies, Raleigh, NC, U.S.A.). Virus was propagated in adult male Fischer-344 rats, and lung homogenates were used for infectivity in these experiments (15). Viral content was analyzed using the MadinDarby canine kidney plaque assay and frozen in aliquots at $-70^{\circ} \mathrm{C}$. Animals were inoculated intranasally with $25 \mu \mathrm{L}$ of
RAIV diluted 1:100 in PBS to $1.9 \times 10^{4} \mathrm{PFU} / \mathrm{mL}$. E. coli endotoxin 0127:B8 was obtained from Sigma Chemical Co. (St. Louis, MO, U.S.A.), diluted with PBS and used in a range of $0.05-2.0 \mathrm{mg} / \mathrm{kg}$ in a single i.p. dose of $0.2 \mathrm{~mL}$.

Animals. Timed pregnant Fischer-344 rat dams, obtained from Charles River Laboratories (Raleigh, NC, U.S.A.) at $15 \mathrm{~d}$ gestation, were allowed to litter in solid-bottom plastic cages with one dam per cage. Animals were maintained at $72 \pm 2^{\circ} \mathrm{F}$, humidity $50 \pm 10 \%$, in Illinois isolation cubicles with 12 -h light-dark cycles and allowed food and water ad libitum. Within $48 \mathrm{~h}$ of birth, rat pups were randomly cross-fostered, and litters were standardized to 10 pups per dam. This research was approved by the Animal Care and Use Committee at the National Institute of Environmental Health Sciences and Duke University.

Mortality studies. Initial experiments were conducted to ascertain mortality, timing between doses, and optimum endotoxin levels to model the pathology of SIDS. Ten-day-old rat pups were infected with $25 \mu \mathrm{L}$ of RAIV given intranasally (16). One to $5 \mathrm{~d}$ after RAIV inoculation, one group of pups per day per dose was given an i.p. endotoxin challenge $(2,0.5,0.2$, or $0.05 \mathrm{mg} / \mathrm{kg}$ ). A second group of pups without previous exposure to RAIV was given the same dose of endotoxin at each time as a control. RAIV controls received virus only on $\mathrm{d}$ 10. Pups were examined every $4 \mathrm{~h}$ after endotoxin for morbidity and mortality. Naïve controls were not given either RAIV or endotoxin.

Additional studies were conducted to establish the critical age at which dual challenge most resembled SIDS. Animals were maintained as above. Pups were infected intranasally with RAIV on d 8, 10, or 14 and then given an endotoxin challenge $(0.5,0.2,0.1$, or $0.05 \mathrm{mg} / \mathrm{kg})$ i.p. $2 \mathrm{~d}$ after RAIV inoculation. A second group of pups was given endotoxin in the same doses and time interval as the first group but without RAIV. Additional controls were inoculated with RAIV only on d 8, 10, or 14. Pups were examined every $4 \mathrm{~h}$ for morbidity and mortality, and deceased animals were removed for necropsy. Adult (8wk-old) rats were similarly challenged with $100 \mu \mathrm{L}$ of RAIV intranasally (15) and endotoxin $(2,0.5,0.2$, and $0.1 \mathrm{mg} / \mathrm{kg})$ i.p. $2 \mathrm{~d}$ after RAIV inoculation.

Mechanistic studies. After establishing that inoculation with RAIV at $10 \mathrm{~d}$ of age followed by endotoxin $0.2 \mathrm{mg} / \mathrm{kg} 2 \mathrm{~d}$ after RAIV caused significant mortality with the lowest morbidity, a series of experiments were developed to examine pathology and evaluate immune variables before death. On d 10 of life, pups were infected with $25 \mu \mathrm{L}$ of RAIV given intranasally. On d 12, RAIV-inoculated and untreated animals were given endotoxin $0.2 \mathrm{mg} / \mathrm{kg}$ i.p. and randomly assigned to groups. Animals were euthanized using $0.1 \mathrm{mg} / \mathrm{kg}$ pentobarbital i.p. 2 , 4,6 , and $8 \mathrm{~h}$ after endotoxin.

Histology. Tissues (liver, spleen, thymus, heart, lung, kidney) were processed, embedded in paraffin, sectioned at 5 to 6 $\mu \mathrm{m}$, and stained with $\mathrm{H} \& \mathrm{E}$ for microscopic examination. A semiquantitative assessment was used to estimate the histopathologic reaction in the affected tissues. The scoring was done without knowing either the identity of the animal or its treatment group ("blind evaluation") based on a method described by Lomnitski et al. (17). Lesions were described and 
scored where appropriate using five semiquantitative grades: 0 , no lesion; 1 , minimal lesion; 2 , mild lesion; 3 , moderate lesion; or 4 , severe lesion. The severity score for each group and lesion was then calculated.

Cell phenotyping. MAbs used for identification of spleen cell surface antigen expression were FITC-conjugated mouse anti-rat CD8a (clone G28, Pharmingen, San Diego, CA, U.S.A.), CD4 (clone w3/25, Serotec, Oxford, U.K.), CD8b (clone 341, Pharmingen), CD11b (clone wt.5, Pharmingen), immunoglobulin kappa-light chain (clone OX-12, Serotec), and phycoerythrin-conjugated mouse anti-rat CD3 (clone G4.18, Pharmingen), MAC (clone HIS36, Pharmingen), NKp-1 (clone 10/78, Pharmingen), and CD45RA (clone OX33, Pharmingen). All antibodies were titrated and used at the concentration found to produce optimal fluorescence.

Five spleens per group were aseptically collected by dissection immediately after anesthesia, placed in RPMI 1640 supplemented with 10\% FCS (Hyclone, Logan, UT, U.S.A.), 1\% L-glutamate, and $1 \%$ penicillin/streptomycin, and kept on ice until processed. Tissue was mechanically dissociated into a single-cell suspension, then washed twice in PBS at room temperature. Cells were counted by hemocytometer in Trypan blue $0.5 \%$ and adjusted to $2 \times 10^{6}$ cells $/ \mathrm{mL}$ in PBS, $10 \% \mathrm{FCS}$, and $0.02 \%$ sodium azide (PBS/FCS/NaAzide).

Cells were double stained for surface antigen expression. Fifty microliters of diluted antibody was added to triplicate wells of a 96-well V-bottom microtiter plate containing $1 \times$ $10^{6}$ cells. After a $1-\mathrm{h}$ incubation at $4^{\circ} \mathrm{C}$ in the dark, cells were washed two times with PBS/FCS/NaAzide and then fixed with PBS/NaAzide $/ 2 \%$ formaldehyde (18). Cells - were counted within $48 \mathrm{~h}$ of staining and analyzed by a fluorescenceactivated cell sorting flow cytometer (Becton Dickinson Immunocytometry Systems, Atlanta, GA, U.S.A.) using Cell Quest 4.1 software. Control samples stained with only one fluorochrome were used to determine the proper color compensation. Dead cells, debris, and RBC were gated out and not included in the results.

Broncheoalveolar lavage fluid. Alveolar cells and fluid was harvested by lavaging the lungs of five animals per group in situ at least five times with $2 \mathrm{~mL}$ of ice-cold, $\mathrm{Ca}^{2+} \mathrm{O}$ and $\mathrm{Mg}^{2+}$-free PBS. Samples were centrifuged for $10 \mathrm{~min}$ at 1500 $\mathrm{rpm}$ at $4^{\circ} \mathrm{C}$, and the supernatant was collected and stored at $-20^{\circ} \mathrm{C}$ for cytokine ELISA measurements (TNF- $\alpha$, IFN- $\gamma$, and IL-12). Cells were resuspended in RPMI containing 10\% FCS, counted by hemocytometer in Trypan blue $0.5 \%$, and adjusted to $5 \times 10^{5}$ cells $/ \mathrm{mL}$ in RPMI- $10 \%$ FCS. One hundred microliters of each sample was transferred to a glass slide, centrifuged at $200 \times g$ for 2 min using a Cytospin 3 (Shandon Inc, Pittsburgh, PA, U.S.A.), and stained with Wright-Giemsa for differential analysis (15).

ELISA. Commercial rat cytokine ELISA kits (Biosource, Camarillo, CA, U.S.A..) were used for measurements of TNF- $\alpha$, IFN- $\gamma$, and IL-12 in serum and BALF samples.

Statistical analysis. Results are presented as mean \pm SD with $n$ equal to the number of animals in each group. Data comparing values of untreated and treated groups were statistically evaluated by $F$ test, and compared between groups by the $t$ test. Mortality rates of treated groups were compared using the $\chi^{2}$ test. Data indicating the incidence of the histopathologic changes were analyzed using Fisher's exact test. Data indicating the severity of the histopathologic changes were analyzed using the Mann-Whitney $U$ procedure.

\section{RESULTS}

\section{Mortality Studies}

Animals in all endotoxin groups were lethargic 4 to $6 \mathrm{~h}$ after endotoxin; however, the only deaths were in pups intranasally inoculated with RAIV on d 10 then given an endotoxin challenge $1,2,3,4$, or 5 d later. Significant mortality, 80, 60, and $80 \%$, was observed in animals dosed at $2 \mathrm{~d}$ after RAIV inoculation with endotoxin $(2,0.5$, and $0.2 \mathrm{mg} / \mathrm{kg}$, respectively), compared with $20 \%$ mortality in pups receiving endotoxin $(0.5$ and $0.2 \mathrm{mg} / \mathrm{kg}$ ) at $1 \mathrm{~d}$ after RAIV inoculation or $0.5 \mathrm{mg} / \mathrm{kg}$ endotoxin at $3 \mathrm{~d}$ after RAIV inoculation ( $p<0.001$; Fig. 1$)$. There were no deaths in the RAIV only or RAIV untreated groups. These studies indicate that the timing of $2 \mathrm{~d}$ between RAIV administration and endotoxin challenge was critical for significant differences in mortality.

In the second experiment, pups were intranasally inoculated with RAIV on d 8, 10, or 14 then given an endotoxin challenge $2 \mathrm{~d}$ later. Significant mortality, 60 and $66 \%$, was observed in 12 -d old animals given endotoxin 0.5 and $0.2 \mathrm{mg} / \mathrm{kg}$, respectively ( $p<0.01 ;$ Fig. 2 ). A smaller number of animals (30 and $20 \%$ ) died at $10 \mathrm{~d}$ of age dosed at $2 \mathrm{~d}$ after RAIV inoculation with endotoxin ( 0.5 and $0.2 \mathrm{mg} / \mathrm{kg}$, respectively). There were no deaths in 16-d-old (Fig. 2) or adult animals (data not shown) dosed $2 \mathrm{~d}$ after RAIV inoculation. There were no deaths in the RAIV only or RAIV untreated groups. There were no deaths in either experiment at the lowest endotoxin level $(0.05 \mathrm{mg} / \mathrm{kg})$. Increasing the endotoxin dose above $0.2 \mathrm{mg} / \mathrm{kg}$ did not increase mortality but had the potential to increase morbidity in endotoxin groups. Mortality differed by age of pups and was greatest at $12 \mathrm{~d}$ of age.

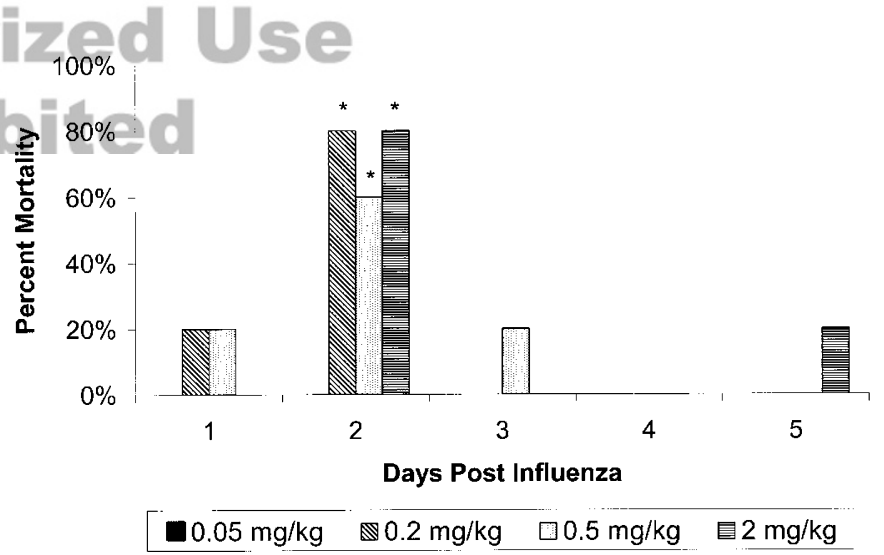

Figure 1. Mortality in rat pups challenged with endotoxin 1-5 d after RAIV inoculation. Ten-day-old rat pups were inoculated with $25 \mu \mathrm{L}\left(1.9 \times 10^{4}\right.$ $\mathrm{PFU} / \mathrm{mL}$ ) of RAIV given intranasally. One to $5 \mathrm{~d}$ after RAIV inoculation, one group of pups per day per dose was given an endotoxin challenge $(2,0.5,0.2$, or $0.05 \mathrm{mg} / \mathrm{kg}$ ) i.p. as described in "Methods." Values for each individual endotoxin dose at 1, 2, 3, 4, and $5 \mathrm{~d}$ after RAIV inoculation were for $2 \mathrm{mg} / \mathrm{kg}$ $(0,80,0,0,20 \%), 0.5 \mathrm{mg} / \mathrm{kg}(20,60,20,0,0 \%), 0.2 \mathrm{mg} / \mathrm{kg}(20,80,0,0,0 \%)$, and $0.05 \mathrm{mg} / \mathrm{kg}(0,0,0,0,0 \%)$. *Significant difference $(p<0.001)$ from other ages at endotoxin doses $2,0.5$, and $0.2 \mathrm{mg} / \mathrm{kg}$ by $\chi^{2}, n=5$. 


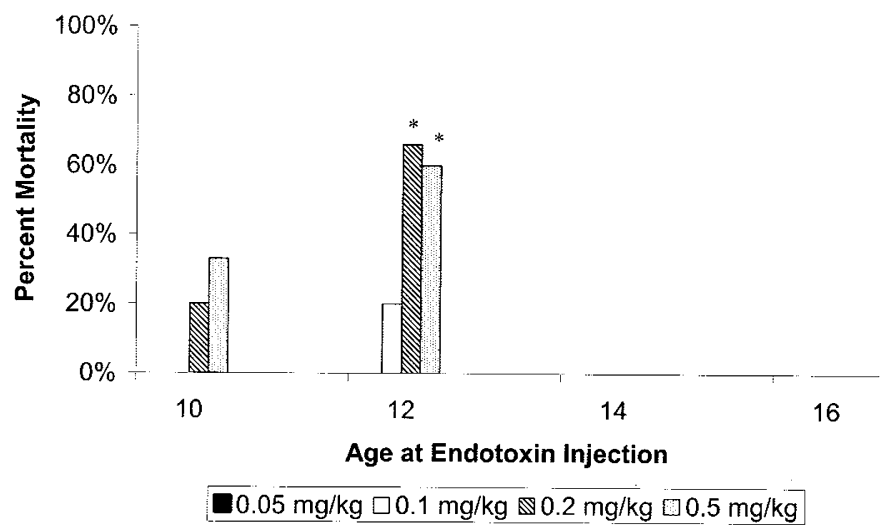

Figure 2. Age-related mortality in rat pups given endotoxin $2 \mathrm{~d}$ after RAIV inoculation. Pups were intranasally inoculated with $25 \mu \mathrm{L}\left(1.9 \times 10^{4} \mathrm{PFU} /\right.$ $\mathrm{mL}$ ) of RAIV given on $\mathrm{d} 8,10$, or 14 of life and then given an endotoxin challenge $(0.5,0.2,0.1$, or $0.05 \mathrm{mg} / \mathrm{kg})$ i.p. $2 \mathrm{~d}$ after RAIV inoculation as described in "Methods." Values for each individual endotoxin dose at 10, 12, and $16 \mathrm{~d}$ after RAIV inoculation were for $0.5 \mathrm{mg} / \mathrm{kg}(33,60,0 \%), 0.2 \mathrm{mg} / \mathrm{kg}$ $(20,66,0 \%), 0.1 \mathrm{mg} / \mathrm{kg}(0,20,0 \%)$, and $0.05 \mathrm{mg} / \mathrm{kg},(0,0,0 \%) .{ }^{*}$ Significant difference $(p<0.01)$ from other ages at endotoxin doses $0.5 \mathrm{mg} / \mathrm{kg}$ and 0.2 $\mathrm{mg} / \mathrm{kg}$ by $\chi^{2}, n=5$.

\section{Mechanistic Studies}

Clinical observations. At each time, endotoxin-treated RAIV-inoculated animals were more severely affected than RAIV untreated animals. At $6 \mathrm{~h}$ after endotoxin, the pups were mildly cyanotic and cool, and adequate cardiac blood samples were more difficult to obtain. It is assumed that they were hypotensive; however, quantitative measurements were not taken. After cardiac puncture at $6 \mathrm{~h}, \mathrm{RAIV}$-inoculated pups continued to bleed without clotting, suggesting early disseminated intravascular coagulation commonly seen in septic shock. At $8 \mathrm{~h}$, RAIV untreated pups were still lethargic and cool but were regaining normal activity. No overt toxicity was seen in either nonendotoxin-exposed control group.

Pathologic findings. Gross pathology of animals was similar within groups for all experiments. Gross examination revealed petechiae in the lungs, subendocardial hemorrhage, lymphoid cell necrosis of the thymic cortex, and pale kidneys in endotoxin-treated RAIV-inoculated animals. All pups still had milk in their stomachs, suggesting a rapid progression to death.

The cumulative incidence of histopathologic findings is presented in Table 1, with mean severity scores shown in Table 2. RAIV-inoculated animals $6 \mathrm{~h}$ after endotoxin showed the most prominent and frequent treatment-related lesions, and therefore, the incidence and severity of the lesions noted in other groups were compared with this group. There were no

Table 1. Incidence of histopathology*

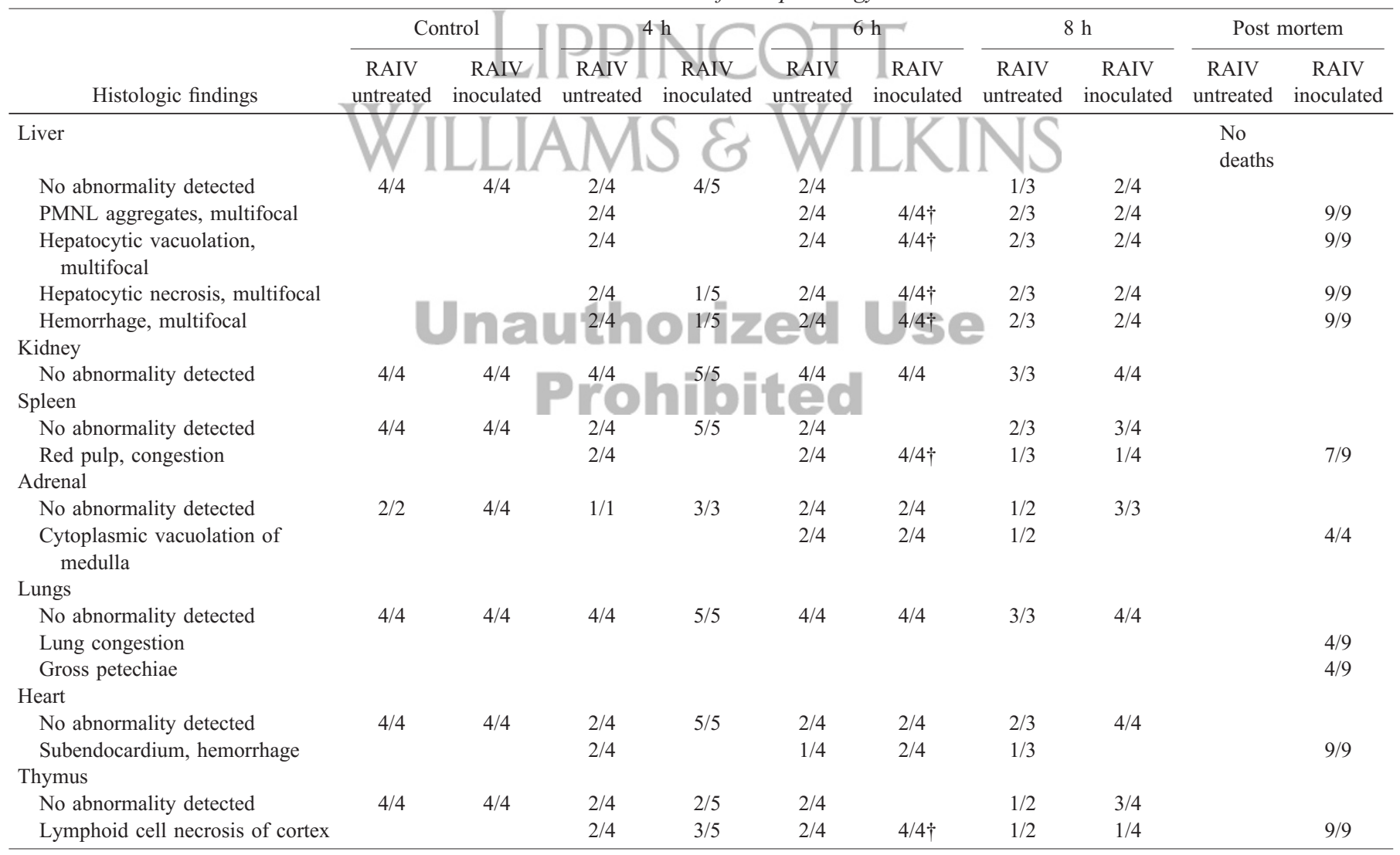

* Incidence of observation/number organs examined (irrespective of severity scores) of selected findings of Fischer-344 rat pups testing the effect of prior RAIV inoculation on endotoxin response. No lesions were detected at $2 \mathrm{~h}$ after endotoxin in either group. Postmortem results represent animals found before autolysis after dual inoculation as described in the "Mortality Studies." There was no mortality in RAIV untreated animals.

$\dagger$ Significant difference $(p<0.03)$ from RAIV-inoculated and either control group untreated and RAIV only by Fisher's exact test.

PMNL, polymorphonuclear leukocytes. 
Table 2. Severity scores for histopathology*

\begin{tabular}{|c|c|c|c|c|c|c|}
\hline \multirow[b]{2}{*}{ Histologic findings } & \multicolumn{2}{|c|}{$4 \mathrm{~h}$} & \multicolumn{2}{|c|}{$6 \mathrm{~h}$} & \multicolumn{2}{|c|}{$8 \mathrm{~h}$} \\
\hline & $\begin{array}{c}\text { RAIV } \\
\text { untreated }\end{array}$ & $\begin{array}{c}\text { RAIV } \\
\text { inoculated }\end{array}$ & $\begin{array}{c}\text { RAIV } \\
\text { untreated }\end{array}$ & $\begin{array}{c}\text { RAIV } \\
\text { inoculated }\end{array}$ & $\begin{array}{c}\text { RAIV } \\
\text { untreated }\end{array}$ & $\begin{array}{c}\text { RAIV } \\
\text { inoculated }\end{array}$ \\
\hline PMNL aggregates, multifocal & $0.5 \pm 0.29$ & $0 \pm 0.0 \ddagger$ & $0.5 \pm 0.29$ & $1 \pm 0.0$ & $0.67 \pm 0.33$ & $0.5 \pm 0.29$ \\
\hline Hepatocytic vacuolation, multifocal & $1 \pm 0.58$ & $0.2 \pm 0.2 \S$ & $1 \pm 0.58$ & $2 \pm 0.0$ & $1 \pm 0.58$ & $1 \pm 0.58$ \\
\hline Hepatocytic necrosis, multifocal & $1 \pm 0.58$ & $0.2 \pm 0.2 \S$ & $1 \pm 0.58$ & $2 \pm 0.0$ & $1.33 \pm 0.67$ & $1 \pm 0.58$ \\
\hline Hemorrhage, multifocal & $0.75 \pm 0.48$ & $0.2 \pm 0.2 \S$ & $1 \pm 0.58$ & $2 \pm 0.0 \|$ & $1 \pm 0.58$ & $0.75 \pm 0.48$ \\
\hline \multicolumn{7}{|l|}{ Spleen } \\
\hline Red pulp, congestion & $0.5 \pm 0.29$ & $0 \pm 0.0 \ddagger$ & $0.75 \pm 0.48$ & $1 \pm 0.0 \|$ & $0.67 \pm 0.67$ & $0.25 \pm 0.25$ \\
\hline \multicolumn{7}{|l|}{ Adrenal } \\
\hline Cytoplasmic vacuolation of medulla & $0 \pm 0.0$ & $0 \pm 0.0$ & $0.5 \pm 0.29$ & $1 \pm 0.58$ & $0.5 \pm 0.5$ & $0 \pm 0.0$ \\
\hline \multicolumn{7}{|l|}{ Heart } \\
\hline Subendocardium, hemorrhage & $0.5 \pm 0.29$ & $0 \pm 0.0$ & $0.5 \pm 0.5$ & $0.5 \pm 0.29$ & $0.33 \pm 0.33$ & $0 \pm 0.0$ \\
\hline \multicolumn{7}{|l|}{ Thymus } \\
\hline Lymphoid cell necrosis of cortex & $0.5 \pm 0.29$ & $0.6 \pm 0.24 \S$ & $0.5 \pm 0.29$ & $2 \pm 0.0 \div q$ & $0.5 \pm 0.5$ & $0.25 \pm 0.25$ \\
\hline
\end{tabular}

* Mean severity of histopathologic findings \pm SD in Fischer-344 rat pups testing the effect of prior RAIV inoculation on endotoxin response. (Severity scores:

0 , no lesion; 1, minimal lesion; 2, mild lesion; 3, moderate lesion; 4, severe lesion).

$\dagger$ Significant difference $(p<0.05)$ compared with 6 h RAIV untreated by Mann-Whitney $U$ test.

$\$$ Significant difference $(p<0.01)$ compared with $6 \mathrm{~h}$ RAIV inoculated by Mann-Whitney $U$ test.

$\S$ Significant difference $(p<0.05)$ compared with $6 \mathrm{~h}$ RAIV inoculated by Mann-Whitney $U$ test.

$\|$ Significant difference $(p<0.01)$ compared with 8 h RAIV inoculated by Mann-Whitney $U$ test.

9/ Significant difference $(p<0.05)$ compared with $8 \mathrm{~h}$ RAIV inoculated by Mann-Whitney $U$ test.

treatment-related lesions in untreated or RAIV only animals and at $2 \mathrm{~h}$ after endotoxin injection.

RAIV-inoculated animals $4 \mathrm{~h}$ after endotoxin injection had lesions in the liver and thymus. Hepatocellular necrosis was minimally observed in a single animal, whereas thymic cortical necrosis was seen in three. There were significant differences in severity scores from the liver $(p<0.05)$, spleen $(p<0.01)$, and thymus $(p<0.05)$ when comparing RAIV-inoculated animals at 4 and $6 \mathrm{~h}$. RAIV untreated animals, $4 \mathrm{~h} /$ after endotoxin injection, displayed lesions in the liver, heart, spleen, and thymus. When compared with $6 \mathrm{~h}$ after endotoxin RAIV-inoculated animals, lesions were similar in nature, but less frequent with reduced severity.

All RAIV-inoculated animals $6 \mathrm{~h}$ after endotoxin injection had lesions in the liver, adrenal, heart, spleen, and thymus. In the liver, multifocal hepatocytic necrosis associated with polymorphonuclear leukocyte infiltration was noted (Fig. 3, $A$ and $B)$. The inflammatory component was minor in contrast to the more prominent necrotic process. Many of the dying cells exhibited cytoplasmic shrinkage and clumped chromatin or presence of extracellular or intracellular apoptotic bodies, cytomorphologic characteristics consistent with apoptotic necrosis (Fig. 3, $C$ and $D$ ) (19). RBC occupied empty spaces left by necrotic hepatocytes and engorged the dilated sinusoids. The cytoplasm of hepatocytes located close to necrotic foci was also finely vacuolated. In the thymus, this treatment regimen was associated with the presence of apoptotic necrotic lymphocytes with hyperbasophilic nuclear debris in the cortex (Fig. $3 E$ ). In the spleen, changes consisted of red pulp congestion. Subendocardial hemorrhage, represented as small foci of extravasated RBC beneath the ventricular endocardium, was observed in the heart. In the adrenal medulla, the same treatment resulted in vacuolation of the chromaffin cells (Fig. $3 F$ ).

RAIV untreated animals $6 \mathrm{~h}$ after endotoxin injection had lesions in the liver, heart, adrenal, spleen, and thymus. When compared with the RAIV- inoculated group, lesions were similar in nature, but were less frequent, with decreased severity. Changes in the thymus were significantly different at $6 \mathrm{~h}$ between the RAIV-inoculated and the RAIV untreated animals $(p<0.05)$.

Animals $8 \mathrm{~h}$ after endotoxin injection, in both RAIVinoculated and RAIV untreated groups, were associated with lesions in the liver, spleen, adrenal, and thymus. When compared with the 6-h RAIV-inoculated group, lesions were of similar nature, but less frequent, and with decreased severity. Significant differences were seen in the severity of lesions in the thymus between the 6- and 8-h RAIV-inoculated animals ( $p$ $<0.05)$.

\section{IES Spleen and Pulmonary Cell Populations}

In experimental groups, several significant differences were found in spleen cell subpopulations after endotoxin administration in 12-d-old pups. For evaluation purposes macrophage subpopulations were defined as $(\mathrm{MAC}+/ \mathrm{CD} 11 \mathrm{~b}+)$ plus $(\mathrm{MAC}+/ \mathrm{CD} 11 \mathrm{~b}-)$ cells and granulocyte subpopulations were defined as $(\mathrm{MAC}-/ \mathrm{CD} 11 \mathrm{~b}+)$ single positive cells. Untreated and RAIV only control animals had similar macrophage numbers in the spleen, 23 and $20 \%$ positive cells, respectively (Table 3). Macrophage cell numbers dropped below control levels in the RAIV-inoculated animals, with the lowest point of $13 \%$ at $4 \mathrm{~h}$ after endotoxin administration, then increasing to $30 \%$ by $8 \mathrm{~h}$. The RAIV untreated animals followed a similar pattern, with a low of $16 \%$ at $4 \mathrm{~h}$, then returning to control levels of $24 \%$ at $8 \mathrm{~h}$ (Table 3). Differences between RAIV untreated pups and RAIV-inoculated pups were most significant at $2 \mathrm{~h}(25 \%$ versus $16 \% ; p<0.001)$ and $8 \mathrm{~h}(24 \%$ versus $30 \% ; p<0.01)$ after endotoxin, respectively. At 8 h, RAIVinoculated numbers were significantly higher than RAIV untreated animals and well above control levels $(p<0.01)$. 

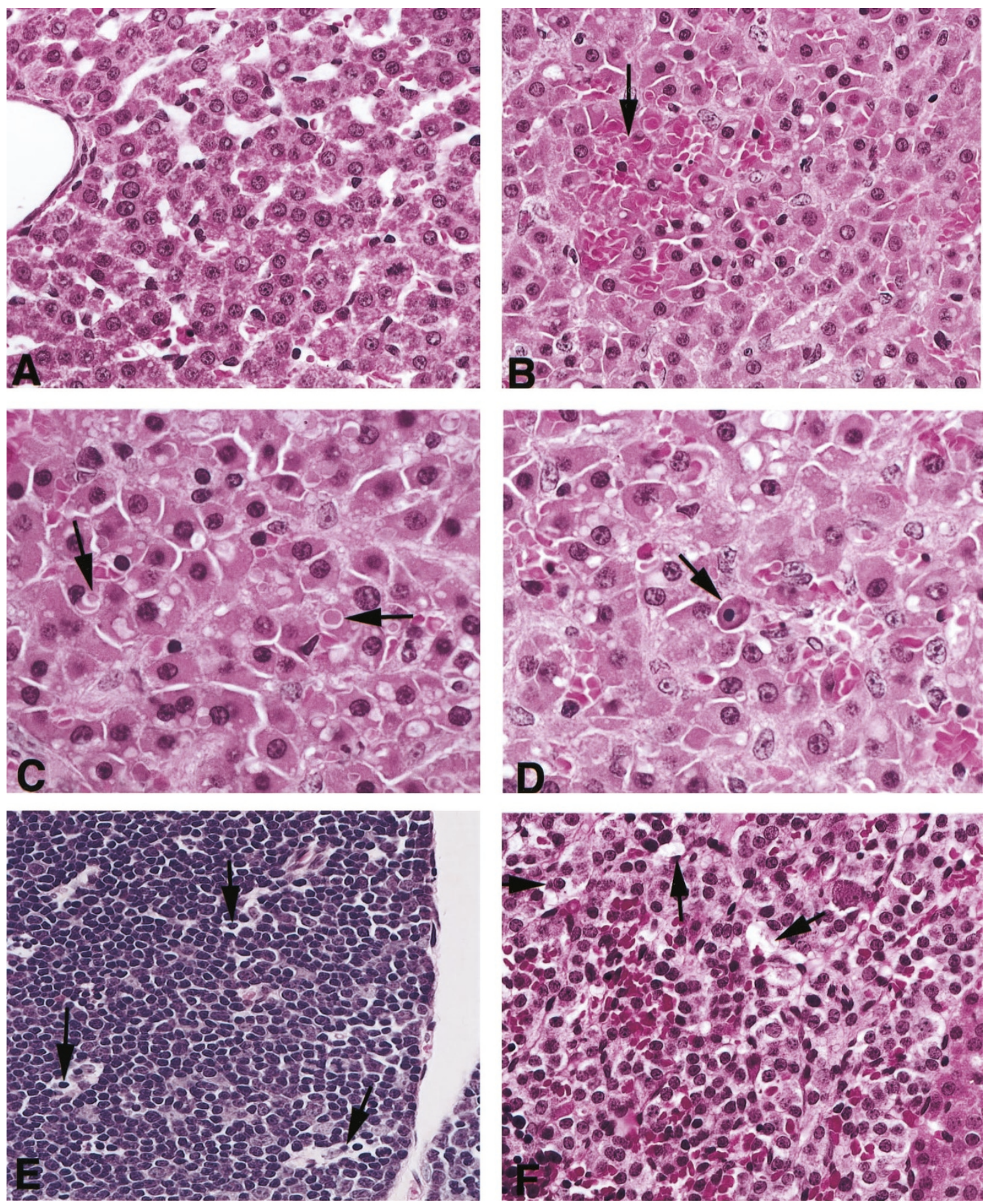

Figure 3. Representative photomicrographs of tissues stained with H\&E taken from RAIV untreated and RAIV-inoculated 12-d-old rat pups $0,2,4,6$, and $8 \mathrm{~h}$ after $0.2 \mathrm{mg} / \mathrm{kg}$ endotoxin as described in "Methods." $A$, H\&E stained liver from an untreated control 12-d-old rat pup; $\times 400 . B$, focal necrosis and hemorrhage (arrow) in the liver $6 \mathrm{~h}$ after endotoxin injection from a 12-d-old rat pup exposed to RAIV and endotoxin; $\times 400$. C, necrotic cell (arrow) in the liver $6 \mathrm{~h}$ after endotoxin injection from a 12-d-old rat pup exposed to RAIV and endotoxin. Note nonchromatin apoptotic body ("apoptotic necrosis") (arrow) within hepatocytes; $\times 600$. D, necrotic cell (arrow) in the liver $6 \mathrm{~h}$ after endotoxin injection from a 12-d-old rat pup exposed to RAIV and endotoxin; $\times 600$. $E$, mild degree of lymphocyte necrosis (arrows) in the cortex of the thymus $6 \mathrm{~h}$ after endotoxin injection from a 12-d-old rat pup exposed to RAIV and endotoxin. $\times 400$; $F$, chromaffin cell cytoplasmic vacuolation (arrow) in the adrenal medulla $6 \mathrm{~h}$ after endotoxin from a 12-d-old rat pup exposed to RAIV and endotoxin; $\times 400$.

Granulocyte numbers were consistent across treatment groups (Table 3).

There was a significant effect of endotoxin on T-lymphocyte numbers in all endotoxin-exposed experimental groups when compared with naïve control or RAIV only animals (ANOVA $F$ test). Table 4 shows a mild decrease in $\mathrm{Th}\left(\mathrm{CD}^{+} / \mathrm{CD}^{+} ; p\right.$
$<0.01)$ and $\mathrm{Ts} / \mathrm{c}\left(\mathrm{CD}^{+} / \mathrm{CD} 8 \mathrm{~b}^{+} ; p<0.01\right)$ populations in the spleen, with lowest levels in each group at $4 \mathrm{~h}$ after endotoxin. Pairwise comparisons using $t$ tests were not significant.

Cell populations identified on Wright-Giemsa stain from BALF showed a predominance of alveolar macrophages with little fluctuation in cell numbers across time or among groups. 
Table 3. Effect of RAIV on macrophage and granulocyte populations in spleen*

\begin{tabular}{|c|c|c|c|c|c|c|c|c|c|c|}
\hline \multirow[b]{2}{*}{ Cell population } & \multicolumn{2}{|c|}{ Control } & \multicolumn{2}{|c|}{$2 \mathrm{~h}$} & \multicolumn{2}{|c|}{$4 \mathrm{~h}$} & \multicolumn{2}{|c|}{$6 \mathrm{~h}$} & \multicolumn{2}{|c|}{$8 \mathrm{~h}$} \\
\hline & $\begin{array}{c}\text { RAIV } \\
\text { untreated }\end{array}$ & $\begin{array}{c}\text { RAIV } \\
\text { inoculated }\end{array}$ & $\begin{array}{c}\text { RAIV } \\
\text { untreated }\end{array}$ & $\begin{array}{c}\text { RAIV } \\
\text { inoculated }\end{array}$ & $\begin{array}{c}\text { RAIV } \\
\text { untreated }\end{array}$ & $\begin{array}{c}\text { RAIV } \\
\text { inoculated }\end{array}$ & $\begin{array}{c}\text { RAIV } \\
\text { untreated }\end{array}$ & $\begin{array}{c}\text { RAIV } \\
\text { inoculated }\end{array}$ & $\begin{array}{c}\text { RAIV } \\
\text { untreated }\end{array}$ & $\begin{array}{c}\text { RAIV } \\
\text { inoculated }\end{array}$ \\
\hline$\% \mathrm{MAC}+\mathrm{CD} 11 \mathrm{~b}+$ & $15 \pm 7.2$ & $12 \pm 5.7$ & $10 \pm 5.3$ & $7 \pm 1.5$ & $5 \pm 1.5$ & $4 \pm 0.2 \hbar$ & $6 \pm 1.9$ & $6 \pm 1.3 t$ & $9 \pm 1.9$ & $11 \pm 4.9$ \\
\hline$\% \mathrm{MAC}-\mathrm{CD} 11 \mathrm{~b}+$ & $12 \pm 2.7$ & $11 \pm 2.9$ & $11 \pm 1.5$ & $10 \pm 1.9$ & $16 \pm 1.7$ & $14 \pm 0.5$ & $16 \pm 4.5$ & $11 \pm 2.5$ & $16 \pm 5.9$ & $15 \pm 8.8$ \\
\hline
\end{tabular}

* Effect of the influenza A virus on the MAC+ (stains the ED2 macrophage population) and CD11b+ (stains a subpopulation of macrophage cells, granulocytes, and neutrophils) subpopulations in the spleen from RAIV untreated and RAIV-inoculated 12-d-old rat pups $2,4,6$, and $8 \mathrm{~h}$ after $0.2 \mathrm{mg} / \mathrm{kg}$ endotoxin as described in "Methods." Results are expressed as mean \pm SD of two replicate experiments on five rats per group.

$\dagger$ Significant difference $(p<0.01)$ comparing (MAC+CD11b-) RAIV untreated and RAIV-inoculated subpopulations at $2 \mathrm{~h}$ after endotoxin by $t$ test.

$\ddagger$ Significant difference $(p<0.05)$ comparing $(\mathrm{MAC}+\mathrm{CD} 11 \mathrm{~b}+)$ RAIV-inoculated control and RAIV-inoculated subpopulations at 4 and $6 \mathrm{~h}$ after endotoxin by $t$ test.

$\S$ Significant difference $(p<0.005)$ comparing $(\mathrm{MAC}+\mathrm{CD} 11 \mathrm{~b}-)$ RAIV-inoculated control and RAIV-inoculated subpopulation at $8 \mathrm{~h}$ after endotoxin by $t$ test.

$\|$ Significant difference $(p<0.05)$ comparing $(\mathrm{MAC}+\mathrm{CD} 1 \mathrm{~b}-$ ) RAIV untreated control and RAIV untreated subpopulations at 2 and $8 \mathrm{~h}$ after endotoxin by $t$ test.

Table 4. Effect of RAIV on T-helper and T-suppressor/cytotoxic populations in spleen*

\begin{tabular}{|c|c|c|c|c|c|c|c|c|c|c|}
\hline \multirow[b]{2}{*}{ T-cell population } & \multicolumn{2}{|c|}{ Control } & \multicolumn{2}{|c|}{$2 \mathrm{~h}$} & \multicolumn{2}{|c|}{$4 \mathrm{~h}$} & \multicolumn{2}{|c|}{$6 \mathrm{~h}$} & \multicolumn{2}{|c|}{$8 \mathrm{~h}$} \\
\hline & $\begin{array}{c}\text { RAIV } \\
\text { untreated }\end{array}$ & $\begin{array}{c}\text { RAIV } \\
\text { inoculated }\end{array}$ & $\begin{array}{c}\text { RAIV } \\
\text { untreated }\end{array}$ & $\begin{array}{c}\text { RAIV } \\
\text { inoculated }\end{array}$ & $\begin{array}{l}\text { RAIV } \\
\text { untreated }\end{array}$ & $\begin{array}{c}\text { RAIV } \\
\text { inoculated }\end{array}$ & $\begin{array}{c}\text { RAIV } \\
\text { untreated }\end{array}$ & $\begin{array}{c}\text { RAIV } \\
\text { inoculated }\end{array}$ & $\begin{array}{c}\text { RAIV } \\
\text { untreated }\end{array}$ & $\begin{array}{c}\text { RAIV } \\
\text { inoculated }\end{array}$ \\
\hline$\% \mathrm{CD}^{+} \mathrm{CD}^{-} \mathrm{b}^{+}$ & $12 \pm 3.7$ & $14 \pm 6.9$ & $14 \pm 8.6$ & $10 \pm 3.0$ & $6 \pm 1.0$ & $5 \pm 2.9$ & $11 \pm 1.7$ & $6 \pm 1.5$ & $5 \pm 3.1$ & $8 \pm 4.1$ \\
\hline
\end{tabular}

* Effect of the influenza A virus on Th $\left(\mathrm{CD}^{+} / \mathrm{CD}^{+}\right)$and Ts/c $\left(\mathrm{CD}^{+} / \mathrm{CD} 8 \mathrm{~b}^{+}\right)$populations in the spleen taken from RAIV untreated and RAIV-inoculated 12-d-old rat pups $0,2,4,6$, and $8 \mathrm{~h}$ after $0.2 \mathrm{mg} / \mathrm{kg}$ endotoxin as described in "Methods." ANOVA demonstrated significant differences in response across time to RAIV for Th $(p<0.01)$ and Ts/c $(p<0.01)$ populations. Results expressed as mean \pm SD of two replicate experiments on five rats per group.

There were no significant changes in cell numbers among the experimental groups (data not shown).

\section{Cytokines}

A statistically significant difference $(p<0.001)$ was seen in serum IFN- $\gamma$, with RAIV untreated pups demonstrating a 2 -fold increase at $6 \mathrm{~h}$ compared with RAIV-inoculated animals (Fig. 4). There was no significant difference in TNF- $\alpha$, IL-12, and IFN- $\gamma$ in BALF across time or among groups (data not shown).

\section{DISCUSSION}

It is clear from our data that a dual challenge, using a nonlethal strain of influenza A virus, RAIV, and a sublethal dose of endotoxin, induced mortality in suckling rat pups that was not seen in animals given endotoxin or RAIV alone. Mortality only occurred when specific criteria such as timing between infectious insults and developmental age of the pup were met. Unexplained death was observed in 12-d-old pups, 7-10 h after endotoxin $(0.2 \mathrm{mg} / \mathrm{kg})$ injection when given $2 \mathrm{~d}$ after influenza with gross and histologic pathology similar to that seen in SIDS infants.

Several animal studies have examined the role of infectious insults in stimulating an unexplained, asymptomatic death. Influenza A virus, when combined with different bacterial toxins, most significantly endotoxin, caused an unexplained death in neonatal ferrets without clinical symptoms or postmortem histologic findings (20). Weanling rats reared in a pathogen-free environment died rapidly after the s.c. injection of bacterial isolates taken from SIDS infants, without terminal signs of illness and with few inflammatory changes in lungs, liver, or heart (21). Siarakas and colleagues (22) observed bradycardia, hypotension, and apnea, with sudden death, in response to several bacterial toxins in a rabbit model, and concluded that bacteria under the right conditions could produce toxins that would cause an endotoxin-like shock.

In addition, a number of studies have investigated the synergy between bacterial toxins and viruses. Influenza A enhanced the secretion of TNF- $\alpha$ and IL-1 in peripheral blood leukocytes incubated with endotoxin (23). Using combinations of bacterial toxins in isolates from SIDS cases, a number of
Figure 4. Effect of RAIV inoculation on IFN- $\gamma$ production in serum samples taken from RAIV untreated and RAIV-inoculated 12-d-old rat pups 0, 2, 4, 6, and $8 \mathrm{~h}$ after $0.2 \mathrm{mg} / \mathrm{kg}$ endotoxin as described in "Methods." Error bars indicate the mean $\mathrm{SD}$, two replicate experiments on five rats per group. *Significant difference $(p<0.001)$ comparing RAIV untreated and RAIVinoculated pups at $6 \mathrm{~h}$ by $t$ test. 
investigators have demonstrated lethal synergy in a chick embryo model (24-26). In general, these models suggest that under certain circumstances a combination of infectious insults can induce mortality. However, these studies have not addressed mechanisms of action such as specific timing between insults, age of susceptibility, or immune variables involved in death.

Pathology of SIDS. In our model, petechiae were found in the lungs and respiratory tract in $44 \%$ of dually infected animals post mortem. However, lung findings were not seen in the mechanistic studies in animals euthanized $8 \mathrm{~h}$ after endotoxin. Generalized signs of inflammation on postmortem examinations of infants dying of SIDS suggested that an infectious agent was involved $(27,28)$. The respiratory tract was the most common site of inflammation, with $80 \%$ of infants dying of SIDS having intrathoracic, subserosal petechial hemorrhages and lung congestion with signs of immune stimulation in mucosa of trachea, duodenum, and nasopharynx $(29,30)$ Lung congestion is often seen in humans or animals after death and may be a sign of agonal changes. These signs would not be expected in animals humanely euthanized with pentobarbital.

Six hours after endotoxin injection, the RAIV-inoculated pups began bleeding from the cardiac puncture site. Subendocardial hemorrhage, represented as a small foci of extravasated $\mathrm{RBC}$ beneath the ventricular endocardium, was seen at $6 \mathrm{~h}$ in $50 \%$ of the RAIV-inoculated animals in the mechanistic studies and in all dually challenged animals in the mortality studies. This peculiar finding of liquid blood in the heart and pericardial hemorrhage has often been described on SIDS autopsy reports (29) and suggests that the acute-phase protein, plateletactivating factor, stimulated in response to IL-6, may play a role in SIDS pathology.

Mild cortical thymocyte necrosis was apparent in all animals; however, it was much more severe in the endotoxintreated, RAIV-inoculated animals. Rambaud and colleagues (3) documented thymus-specific histologic changes such as cortical thymocyte necrosis in $63 \%$ of SIDS infants; these findings are suggestive of a steroid-mediated stress response. Stress-induced changes in the thymus can occur as rapidly as $3 \mathrm{~h}$ after insult and are characterized by a sudden reduction in cortical lymphocytes with a decrease in cortical volume accomplished by cell migration, apoptosis, and decreased mitotic rate (31). These findings are similar to those observed after a severe acute infection; however, in SIDS, as in our model, the prior history and symptoms did not adequately address the severity of the response (3). There is some controversy about the presence of thymic changes in SIDS; however, it is logical that minor thymic necrosis could be caused by agonal stressors (32). More recent work lends credence to this line of thought (3).

The cause of morbidity in our model was presumed to be circulatory disturbance and shocklike effects because of the absence of specific or major tissue damage in our studies. Vascular congestion in the liver and spleen was consistent with endotoxin exposure and with the release of various cytokines and reactive nitrogen species that may have led to circulatory collapse. Cell death in the liver and adrenal glands may have been related to cytokines, particularly TNF- $\alpha$, or alternatively the direct effect of endotoxin or oxidative stress with corticosteroid release (33). Organ pathology, in particular signs of apoptosis, is often described as a response to an acute increase of reactive nitrogen species such as NO (34). Histologic evaluation suggested that mortality in our model was more likely related to a systemic event rather than lung-specific damage.

Immune response. Our data clearly identified age as a key risk factor related to mortality in this model. It has been hypothesized that changes in the developing immune system may have stimulated a more dramatic response because of its immature nature or inability to regulate the effects of such factors as TNF- $\alpha$, IFN- $\gamma$, and NO. Mortality was most significant between 10 and $16 \mathrm{~d}$ of age (Fig. 2). Adult rats did not succumb to the dual infectious challenge. Because of the rapid progression to death after endotoxin injection, it is believed that an innate immune response is implicated.

The peak age for SIDS in humans (2 to $6 \mathrm{mo}$ ) corresponds to a similar immune interval in rats (10 to $20 \mathrm{~d}$ ), a time of early response to both bacterial and viral antigens. Mature macrophages are present in the liver and thymus of neonatal rat pups; however, it is believed that their ability to present antigen is delayed (35). Rat pups begin to respond to heterologous erythrocytes starting around $10 \mathrm{~d}$ of age and by $20 \mathrm{~d}$ are able to make IgM to sheep RBC at approximately $40 \%$ of the adult level (36). In humans, the response to different antigens varies but does not provide a strong antibody response until 4 to 6 mo of age. Our data suggest that early in infancy, the immaturity of immune function could be altered by viral infection and the cascade of events important for a protective response to endotoxin may not occur.

Endotoxin-induced septic shock is stimulated by proinflammatory cytokines, primarily TNF- $\alpha$, IL- 1 , IL-6, and IFN- $\gamma$, that can trigger a cascade of events leading to edema, systemic collapse, decreased blood volume, disseminated intravascular coagulation, organ failure, and death (37). However, recent research has shown that this process is far more complicated than previously thought (38). There appears to be a fine balance between proinflammatory and antiinflammatory stimulation (39). If this balance cannot be maintained, as seen in our model, a sequence of events will follow that include shock, apoptosis, organ dysfunction, immune suppression, and even death (40). Priming of the immune system or preexisting conditions associated with abnormal cytokine levels are likely to result in disequilibrium (38). It is reasonable to believe that SIDS fits within this paradigm of septic shock, as proinflammatory cytokines have been found at higher than normal levels in the body fluids and tissues of infants dying of SIDS (9, 41, 42).

Multiple organ dysfunction after increased release of inflammatory cytokines and NO, via the formation of peroxynitrite, results in apoptosis and necrosis of tissue and glucocorticoid release from the adrenal cortex into the circulation. Organspecific cell death with increased apoptotic rates and thymic stress changes, as seen in our model, are common pathologic findings $(34,43)$. It has been suggested that $\mathrm{NO}$ is responsible for some of the organ damage described in autopsy reports of infants dying of SIDS (44) 
iNOS and NO are also a part of the immune response to viral infection (45). Although most iNOS is stimulated by IFN- $\gamma$, some viruses, including influenza A, can stimulate iNOS directly without proinflammatory cytokines (33). In influenza A viral infections, iNOS-stimulated inflammation is an important cause of mortality rather than the cytopathic effects of the virus (46). Although IFN- $\gamma$, TNF- $\alpha$, and viral replication can induce $\mathrm{NO}$, our data showed lower serum levels of IFN- $\gamma$ in the RAIV-inoculated pups.

Developmental changes in the innate immune response by the macrophage and production of TNF- $\alpha$ remains a potential cause of mortality in this model. A number of in vitro studies have shown that influenza A provides a potent signal for TNF- $\alpha$ production in macrophages after exposure to very low levels of endotoxin. This was directly related to a priming effect which occurred via 1) an increase in TNF- $\alpha$ gene activation, 2) interference with transcription repressor proteins, or 3) stabilization of TNF- $\alpha$ mRNA, resulting in a higher than normal release of TNF- $\alpha$ in response to endotoxin (47-49). Any of these events have the potential to alter the cytokine environment and trigger a lethal response to endotoxin.

\section{CONCUSIONS}

We have established a dual challenge model that results in an unexplained death, pathology, organ damage, and vascular collapse similar to that seen in SIDS. In this model, influenza A virus altered the normal immune response to endotoxin and increased mortality in 12-d-old rat pups. The concept of exacerbation of immune response to bacterial insult after viral preinfection is not new in the literature, although the mechanism has not been clearly elucidated $(10-12)$. How this may be effected by a developing immune response is likewise unclear. We are in the process of investigating the molecular events underlying the immune dysregulation in this model. It is apparent that this is a complex process involving numerous factors in multiple systems in which minor alterations in regulatory mechanisms may have large effects. Ullino

Acknowledgment. The authors thank Dr. Gary Burleson (Burleson Research Technologies, Raleigh, NC, U.S.A.) for his contribution to this work and generous donation of RAIV.

\section{REFERENCES}

1. Blackwell CC, Weir DM 1999 The role of infection in sudden infant death syndrome. FEMS Immunol Med Microbiol 25:1-6

2. Willinger M, James LS, Catz C 1991 Defining the sudden infant death syndrome (SIDS): deliberations of an expert panel convened by the National Institute of Child Health and Human Development. Pediatr Pathol 11:677-684

3. Rambaud C, Guibert M, Briand E, Grangeot-Keros L, Coulomb-L'Herminé A, Dehan M 1999 Microbiology in sudden infant death syndrome (SIDS) and other childhood deaths. FEMS Immunol Med Microbiol 25:59-65

4. Harrison LM, Morris JA, Telford DR, Brown SM, Jones K 1999 The nasopharyngeal bacterial flora in infancy: effects of age, gender, season, viral upper respiratory tract infection and sleeping position. FEMS Immunol Med Microbiol 25:19-28

5. Crawley BA, Morris DB, Drucker DB, Barson AJ, Morris J, Knox WF, Oppenheim BA 1999 Endotoxin in blood and tissue in the sudden infant death syndrome. FEMS Immunol Med Microbiol 25:131-135

6. Wilson CE 1999 Sudden infant death syndrome and Canadian Aboriginals: bacteria and infections. FEMS Immunol Med Microbiol 25:221-226

7. Fleming KA 1992 Viral respiratory infection and SIDS. J Clin Pathol 45:29-32

8. Lindsay JA, Johnson HM, Wallace FM, Soos JM 1994 Can superantigens trigger sudden infant death? Med Hypotheses 43:81-85
9. Vege A, Rognum TO 1999 Inflammatory responses in sudden infant death syndrome - past and present views. FEMS Immunol Med Microbiol 25:67-78

10. Davison VE, Sanford BA 1981 Adherence of staphylococcus aureus to influenza A virus-infected Madin-Darby canine kidney cell cultures. Infect Immun 32:118-126

11. Sanford BA, Ramsay MA 1987 Bacterial adherence to the upper respiratory tract of ferrets infected with influenza A virus. Exp Biol Med 185:120-128

12. Wadowsky RM, Mietzner SM, Skoner DP, Doyle WJ, Fireman P 1995 Effect of experimental influenza A virus infection on isolation of Streptococcus pneumoniae and other aerobic bacteria from the oropharynges of allergic and nonallergic adult subjects. Infect Immun 63:1153-1157

13. Morris JA, Haran D, Smith A 1987 Hypothesis: common bacterial toxins are a possible cause of the sudden infant death syndrome. Med Hypotheses 22:211-222

14. Molony N, Blackwell CC, Busuttil A 1999 The effect of prone posture on nasal temperature in children in relation to induction of staphylococcal toxins implicated in sudden infant death syndrome. FEMS Immunol Med Microbiol 25:109-113

15. Ehrlich JP, Burleson GR 1991 Enhanced and prolonged pulmonary influenza virus infection following phosgene inhalation. J Toxicol Environ Health 34:259-273

16. Dye JA, Morgan KT, Neldon DL, Tepper JS, Burleson GR, Costa DL 1996 Characterization of upper respiratory disease in rats following neonatal inoculation with a rat-adapted influenza virus. Vet Pathol 33:43-54

17. Lomnitski L, Nyska B, Ben-Shaul V, Maronpot R, Haseman J, Harrus T, Bergman M, Grossman S 2000 Effects of antioxidants apocynin and the natural water-soluble antioxidant from spinach on cellular damage induced by lipopolysaccharide in the rat. Toxicol Pathol 28:580-587

18. Gehrs BC, Riddle MM, Williams WC, Smialowicz RJ 1997 Alterations in the developing immune system of the F344 rat after perinatal exposure to 2,3,7,8tetrachlorodibenzo-p-dioxin: II. Effects on the pup and the adult. Toxicology 122: $229-240$

19. Levin S, Bucci TJ, Cohen SM, Fix AS, Hardisty JF, LeGrand EK, Maronpot RR, Trump BF 1999 The nomenclature of cell death: recommendations of an ad hoc committee of the Society of Toxicologic Pathologists. Toxicol Pathol 27:484-490

20. Jakeman KJ, Rushton DI, Smith H, Sweet C 1991 Exacerbation of bacterial toxicity to infant ferrets by influenza virus: possible role in sudden infant death syndrome. J Infect Dis 163:35-40

21. Lee S, Barson AJ, Drucker DB, Morris JA, Telford DR 1987 Lethal challenge of gnotobiotic weanling rats with bacterial isolates from cases of sudden infant death syndrome (SIDS). J Clin Pathol 40:1393-1396

22. Siarakas S, Damas E, Murrell WG 1995 Is cardiorespiratory failure induced by bacterial toxins the cause of sudden infant death syndrome? Studies with an animal model (the rabbit). Toxicon 33:635-649

23. Lundemose JB, Smith H, Sweet C 1993 Cytokine release from human peripheral blood leucocytes incubated with endotoxin with and without prior infection with influenza virus: relevance to the sudden infant death syndrome. Int $\mathrm{J}$ Exp Pathol 74:291-297

24. Drucker DB, Aluyi HS, Morris JA, Telford DR, Gibbs A 1992 Lethal synergistic action of toxins of bacteria isolated from sudden infant death syndrome. J Clin Pathol 45:799-801

25. Sayers NM, Drucker DB, Morris JA, Telford DR 1995 Lethal synergy between toxins of staphylococci and enterobacteria: implications for sudden infant death syndrome. J Clin Pathol 48:929-932

26. Sayers NM, Drucker DB, Morris JA, Telford DR 1996 Significance of endotoxin in lethal synergy between bacteria associated with sudden infant death syndrome: follow up study. J Clin Pathol 49:365-368

27. Williams AL, Uren EC, Bretherton L 1984 Respiratory viruses and sudden infant death. BMJ Clin Res Ed 288:1491-1493

28. Emery JL 1986 Cot deaths in Australia, 1985. Med J Aust 144:469-473

29. Stoltenberg L, Saugstad OD, Rognum TO 1992 Sudden infant death syndrome victims show local immunoglobulin $\mathrm{M}$ response in tracheal wall and immunoglobulin A response in duodenal mucosa. Pediatr Res 31:372-375

30. Stoltenberg L, Vege A, Saugstad OD, Rognum TO 1995 Changes in the concentration and distribution of immunoglobulin-producing cells in SIDS palatine tonsils. Pediatr Allergy Immunol 6:48-55

31. Middleton G, Reid LE, Harmon BV 1994 Apoptosis in the human thymus in sudden and delayed death. Pathology 26:81-89

32. Valdes-Dapena M, McFeeley P, Hoffman H, Franciosi R, Allison D, Jones M, Hunter J 1993 Histopathology Atlas for the Sudden Infant Death Syndrome. Armed Forces Institute of Pathology, Washington, DC, pp 93-299

33. Akaike T, Maeda H 2000 Nitric oxide and virus infection. Immunology 101:300-308

34. Liaudet L, Soriano FG, Szabo C 2000 Biology of nitric oxide signaling. Crit Care Med 28:N37-N52

35. van Rees EP, Dijkstra CD, Sminia T 1990 Ontogeny of the rat immune system: an immunohistochemical approach. Dev Comp Immunol 14:9-18

36. McGhee JR, Michalek SM, Ghanta VK 1975 Rat immunoglobulins in serum and secretions: purification of rat $\operatorname{IgM}, \operatorname{IgA}$ and $\operatorname{IgG}$ and their quantitation in serum, colostrum, milk and saliva. Immunochemistry 12:817-823

37. Horns KM 2000 Neoteric physiologic and immunologic methods for assessing early-onset neonatal sepsis. J Perinat Nurs 13:50-66

38. Bone RC, Grodzin CJ, Balk RA 1997 Sepsis: a new hypothesis for pathogenesis of the disease process. Chest 112:235-243

39. Goldie AS, Fearon KC, Ross JA, Barclay GR, Jackson RE, Grant IS, Ramsay G, Blyth AS, Howie JC 1995 Natural cytokine antagonists and endogenous antiendotoxin core antibodies in sepsis syndrome. The Sepsis Intervention Group. JAMA 274:172-177

40. Rangel-Frausto MS, Pittet D, Costigan M, Hwang T, Davis CS, Wenzel RP 1995 The natural history of the systemic inflammatory response syndrome (SIRS). A prospective study. JAMA 273:117-123 
41. Vege A, Rognum TO, Scott H, Aasen AO, Saugstad OD 1995 SIDS cases have increased levels of interleukin-6 in cerebrospinal fluid. Acta Paediatr 84:193-196

42. Vege A, Rognum TO, Aasen AO, Saugstad OD 1998 Are elevated cerebrospinal fluid levels of IL-6 in sudden unexplained deaths, infectious deaths and deaths due to heart/lung disease in infants and children due to hypoxia? Acta Paediatr 87:819-824

43. Papathanassoglou ED, Moynihan JA, Ackerman MH 2000 Does programmed cell death (apoptosis) play a role in the development of multiple organ dysfunction in critically ill patients? A review and a theoretical framework. Crit Care Med 28:537549

44. Reid G, Tervit H 2000 Sudden infant death syndrome: hypothalamic failure to sense elevated blood pyrogens. Med Hypotheses 54:84-90

45. Karupiah G, Xie QW, Buller RM, Nathan C, Duarte C, MacMicking JD 1993 Inhibition of viral replication by interferon-gamma-induced nitric oxide synthase. Science 261:1445-1448
46. Nathan C 1997 Inducible nitric oxide synthase: what difference does it make? J Clin Invest 100:2417-2423

47. Gong JH, Sprenger H, Hinder F, Bender A, Schmidt A, Horch S, Nain M, Gemsa D 1991 Influenza A virus infection of macrophages. Enhanced tumor necrosis factoralpha (TNF-alpha) gene expression and lipopolysaccharide-triggered TNF-alpha release. J Immunol 147:3507-3513

48. Nain M, Hinder F, Gong JH, Schmidt A, Bender A, Sprenger H, Gemsa D 1990 Tumor necrosis factor-alpha production of influenza A virus-infected macrophages and potentiating effect of lipopolysaccharides. J Immunol 145:1921-1928

49. Nansen A, Jensen T, Christensen JP, Andreasen SO, Ropke C, Marker O, Thomsen AR 1999 Compromised virus control and augmented perforin-mediated immunopathology in IFN-gamma-deficient mice infected with lymphocytic choriomeningitis virus. J Immunol 163:6114-6122

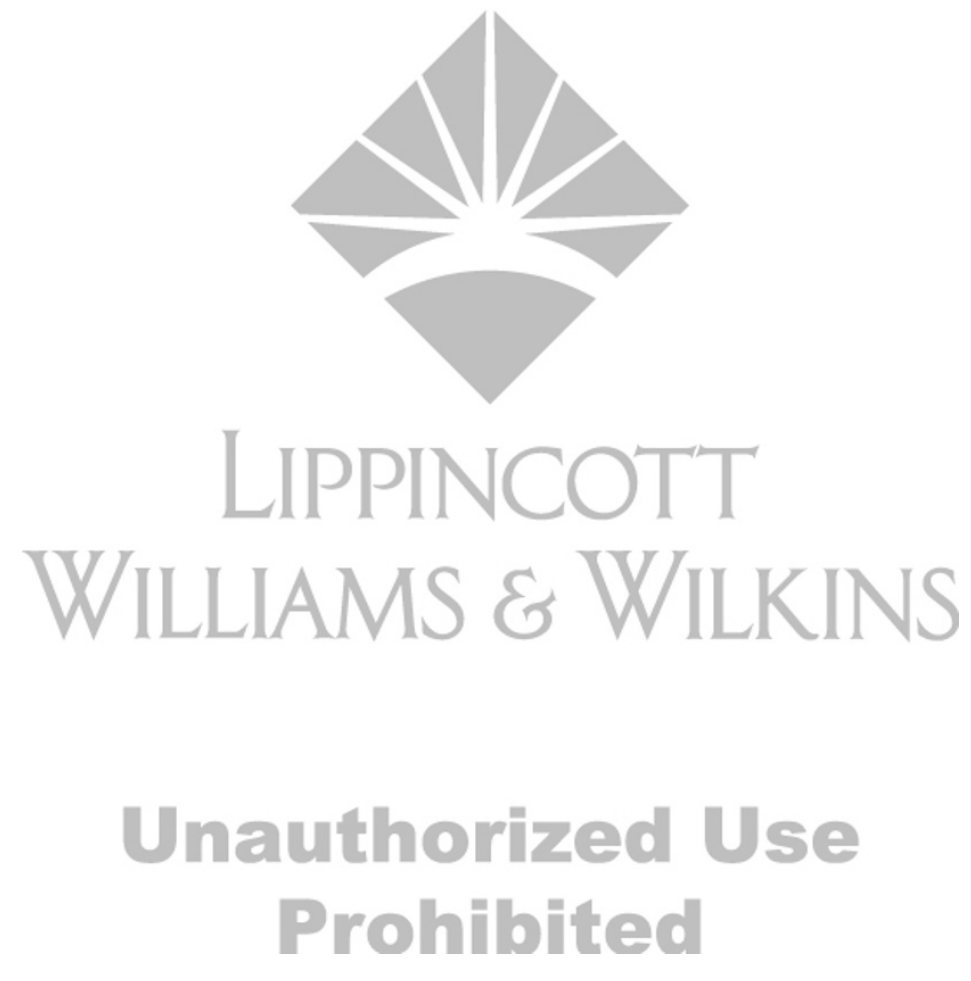

